\title{
Textos poéticos sobre la emancipación de la mujer sefardí en el mundo de los Balcanes *
}

\author{
Elena Romero \\ ILC - CSIC, Madrid
}

En el presente artículo se editan cuarenta textos poéticos en judeoespañol (poemas, coplas y canciones tradicionales), en su mayoría inéditos, que ilustran sobre el proceso de emancipación de la mujer sefardí del Imperio otomano y de los Balcanes desde las postrimerías del siglo XIX en adelante, contemplado por la mirada crítica de los autores del los textos, siempre hombres. Tras una primera canción introductoria, los textos poéticos se organizan bajo epígrafes que ilustran sobre los siguientes temas: 1) la transformación del mundo ambiente, 2) las nuevas modas y los lujos, 3) los bailes modernos, 4) las relaciones entre chicos y chicas: proceso de seducción, 5) la elección de novio, 6) el problema de las dotes y 7) la vida familiar tras la boda. El artículo se completa con los pertinentes glosario y bibliografía.

Palabras ClAVE: judeoespañol; poesía; canciones tradicionales; coplas; Imperio otomano; estudios de mujeres.

Poetical Texts Concerning the Emancipation of the Shepardic Women in the Balkans.Edition of forty Judeo-Spanish poetical texts (poems, Coplas and traditional songs), for the most part unpublished yet. These texts are used for illustrating the emancipation process of the sephardic women in the Ottoman Empire and the Balkans from the end of the $19^{\text {th }}$ century on, always from the critical perspective of their male authors. After a first introductory poem, the texts are organized according to the following topics: 1) Transformation of the general environment; 2) New fashions and luxuries; 3) Modern dance; 4) Relationship between boys and girls; 5) Choosing the groom; 6) The dowry; 7) Familial life after wedding. A glossary and the bibliography are included at the end.

KeYwords: Judeo-Spanish; Poetry; Traditional Songs; Coplas; Ottoman Empire; Women Studies.

A principios de septiembre de 2008 he participado en el XVIII Curso de verano organizado en Toledo por la Asociación de Amigos del Museo Sefardí y por la Universidad de Castilla-La Mancha, curso que en esta ocasión y dirigido por Yolanda Moreno Koch, llevaba por título: «Hijas de Israel, mujeres de Sefarad: De las aljamas de Sefarad al drama del exilio».

* El presente artículo se ha elaborado dentro del Proyecto de Investigación «Sefarad siglo XXI (2005-2007): Edición y estudio filológico de textos sefardíes» (MEC, DGS, HUM2005-01747/FILO). 
Mi conferencia en el curso se ocupaba de «La emancipación de la mujer sefardí de los Balcanes a través de textos poéticos» y para ilustrarla me servía de 39 poemas de diversas categorías: canciones tradicionales, coplas y poemas de autor. Pero, ya que el tiempo de mi intervención no daba para tanto, allí me limité a leer sólo algunos pasajes de los textos seleccionados. Y como también su edición completa rebasaría las páginas que por elemental lógica deberé consumir en las Actas del curso, he optado por desdoblar los materiales y ocuparme aquí exclusivamente de dicha edición; en la mencionada conferencia encontrará el lector interesado mis comentarios a los textos, que aquí omito.

En mi «Emancipación», y tras una introducción (ilustrada con el texto núm. 1), usaba los restantes materiales para documentar los siguientes temas: 1) la transformación del mundo ambiente (textos núms. 2-5); 2) las nuevas modas y los lujos (núms. 6-13, el núm. 7bis no figuraba en «Emancipación»); 3) los bailes modernos (núms. 14-16); 4) las nuevas relaciones entre chicos y chicas (núms. 17-26); 5) la elección de novio (núms. 27-32); 6) el problema de las dotes (núms. 33-37); y 7) la vida familiar tras la boda (núms. 38-39). En cada apartado procuraba ordenar los textos cronológicamente. Esa misma ordenación temática es la que sigue este artículo; el porqué de tal ordenación y mi justificación del paso de unos temas a otros tendrán que leerlo los interesados en mi citada conferencia cuando ésta se publique.

Antes de pasar adelante conviene advertir que, como veremos, muy frecuentemente los temas propuestos aparecen entremezclados en un mismo poema; los distribuyo en uno u otro apartado según cuál sea a mi entender el tema mayoritario del texto.

Hagamos ahora un breve repaso del material que ahora publico. De los 40 textos (39 más uno numerado bis) mencionados, la mayoría (36) están representados en una sola versión y sólo cuatro lo están en varias: 1 Trabajos en 3, 2 Nueva en 2, 14 Charlestón en 2, y 35 Mal dotes en 4, lo que hace un total de 47 versiones manejadas.

De esos 40 textos: también la mayoría (27) son poemas, los más (26) destinados a interpretarse con melodía (núms. 2-6, 8, 11, 15-26, 30-32, 35-37 y 39) y uno en que tal circunstancia no me consta (núm. 7bis); 11 son canciones más o menos tradicionales (núms. 1, 7, 9-10, 14, 27-29, 33-34 y 38) y 2 son coplas (núms. 12-13).

Y asimismo, la mayoría (29) de las 47 versiones usadas me han llegado impresas (núms. 2A, 3-6, 7bis, 8, 11-13, 15-26, 30-32, 35A, 36-37 y 39); en tanto que 15 son versiones orales (núms. 1A-C, 2B, 9-10, 14A-B, 27-28, 34-35 у 38); y 3 de ellas son manuscritas (núms. 7, 29 y 33).

Finalmente, de las 47 versiones: 10 las he tomado prestadas de otros editores (núms. 1A-C, 4, 14A-B, 27-28, 34 y 35B), con los que contraigo una deuda de gratitud; 6 las habían editado ya otros colegas, pero he tenido acceso a los textos 
originales y ofrezco a veces lecturas diferentes (núms. 3, 6, 25, 29, 33 y 35A); una la había publicado otra colega, pero en otra versión (10); una la he editado yo misma (núm. 2A); y 29 permanecían hasta ahora inéditas (núms. 2B, 5, 7, 7bis, 8-9, 11-13, 15-24, 26, 30-32 y 35-39).

En cuanto a la autoría, 11 textos (núms. 1, 7, 9-10, 14, 27-29, 33-34 y 38), todos ellos canciones tradicionales, son anónimos, y también lo son las 2 únicas coplas del grupo (núms. 12-13); otros 8 textos aparecen firmados con seudónimos: «Empostemado» (núm. 4); «El paitán de La Gata» (núm. 11); «Siyac» (núm. 15), identificado por Rivka Havassy -según datos comunicados a Conejero «Cantes satíricos» (nota 13)- como Efrayim Siyón; «Mošico» (núms. 16 y 22), a quien Bunis Voices (pp. 266) identifica con Mošé Abraham Caźés (Gaśóś, vid. infra); «Conjá» (núm. 18); «Lionel de Mesoï» (núm. 23); y «'Aní» (núm. 32). Sí conozco la autoría de los restantes 19 textos: uno lo escribió Abraham A. Cappon (núm. 6), otro Šelomó Šalem (núm. 7bis), dos Alexandro Pérez (núms. 8 y 17), y la parte del león corresponde a Ŝạic y Gaśóś (seudónimos de Ṣ̂ạic ben Nehamá Gueršón y del ya citado Mošé ben Abraham Caźés, respectivamente), a los cuales corresponden 15 poemas (núms. 2-3. 5, 19-21, 24-26, 30-31, 35-37 y 39).

Sobre los criterios de edición cabe hacer algunas precisiones. Salvo en un caso (núm. 6) y por mor de la igualdad, los textos que me han llegado en caracteres latinos los adecuo al sistema de transcripción de la aljamía hebrea propio de la revista Sefarad. Los títulos de los textos son mayoritariamente míos y así también la acentuación, puntuación y versalización. Y, finalmente, en los casos en que las melodías de los textos se indican mediante frases en neogriego o en turco que no he podido descifrar, las reproduzco en aljamiado añadiendo una transcripción «a la fonética».

Pasemos ya a la edición de los textos.

\section{INTRODUCCIÓN}

Como ya he mencionado, el texto que sigue, por desarrollar de forma general el tema de las tareas domésticas, me servía en «Emancipación» como preámbulo a todo el conjunto.

\section{Los trabajos de la semana}

El texto procede de las siguientes tres fuentes:

- A: Versión oral probablemente de Salónica, publicada en caracteres latinos por Attias Cancionero núm. 127 (pp. 221-221), con traducción al hebreo. Aunque no se indica fuente, en el índice de nombres (p. 305) el número del texto aparece atribuido a Yişḥac Gateño (Salónica) ${ }^{1}$.

${ }^{1}$ Vid. también Atтias Cancionero pp. 38 (hb.) y 325 (esp.). Al final del artículo recojo la bibliografía citada abreviadamente. 
- B: Versión oral recogida por Hemsi a Mošé Capón (Salónica 1932) y publicada en caracteres latinos en Hemsi Cancionero núm. 133 (pp. 318-319).

- C: Versión oral de Flory Jagoda (Nueva York, originaria de Vlasenica, Bosnia), según el texto de su disco LP (autora de la música) y publicada en caracteres latinos por Elazar Romancero (p. 114: cabecera El bastidor; con datos adicionales en p. 330).

Se trata de una canción paralelística, que en la versión A consta de 6 estrofas y en la B de 7, ambas con estribillo, de tres versos en A y de cuatro en B, siendo igual el segundo verso de todas las estrofas al tercero del estribillo; la versión C consta de 2 estrofas en las que es difícil rastrear el estrofismo original. Bunis Voices (pp. 476-477) publica otra versión oral de Salónica de 4 estrofas, a la que sigue una nueva de 8 versos, remedo de la tradicional y reinventada para la columna del periódico Acción donde apareció, en la que los vs. 3 y 7 repiten el estribillo tradicional reducido ahora a un sólo verso: «Marido así viváš vos».

Attias Cancionero dice (p. 221) que se trata de un texto muy antiguo y difundido, en el que se reflejan los trabajos de las mujeres de las capas populares y medias de la población, las cuales carecían de toda ayuda externa. Por su parte Hemsi Cancionero, quien la agrupa entre las canciones de pasatiempo, indica (p. 319) que la melodía es probablemente de la segunda mitad del siglo XIX con estética griega, adoptada de algún cante popular de los griegos de Asia Menor, especialmente de Esmirna, y que él mismo llegó a escucharla cuando era muy joven. En su versión se indica mediante bis la repetición de los versos 2 y 6 de estr. 1 .

Además, Pedrosa en su comentario a la versión de Hemsi Cancionero señala (p. 198) la difusión panhispánica ${ }^{2}$ de la canción y según me informa existen también versiones en inglés y en francés.

\section{Versión 1.A}

1 Día de alhad lavo y espando, marido, sí yiváš vos

¿Y cuándo que labre

este lindo bastidor?, maridico, sí yiváš vos.

2 Día de lunes duḅlo y guadro, marido, sí viváš vos.

¿Y cuándo?, etc.

\footnotetext{
${ }^{2}$ Vid. allí bibliografía de otras versiones señaladas por Pedrosa; y asimismo el artículo de FRAILE GIL - WeIch-ShahaK «Trabajos».
} 
3 Día de martes esponjo y sacudgo, marido, sí yiváš vos.

$$
\text { ¿Y cuándo?, etc. }
$$

4 Día de miércoles eśmerzo y guiśo, marido, si viváš vos.

¿Y cuándo?, etc.

5 Día de jueves no vo lo digo ${ }^{3}$ marido, sí yiváš vos.

¿Y cuándo?, etc.

6 Día de viernes forno y enforno marido, sí yiváš vos.

¿Y cuándo?, etc.

\section{Versión 1.B}

1 Día de alhad torno y vis̀ito ${ }^{4}$, marido, así ỵiváš vos.

¿Y cuándo queréš que labre

este lindo bastidor?

Marido, así yiváš vos, maridico, así ỵiváš vos.

2 Día de lunes paso colada, marido, así yiváš vos.

¿Y cuándo queréš que labre

este lindo bastidor?

Marido, así yiváš vos, maridico, así yiváš vos.

3 Día de martes la buigo y la enǰaguo, marido, así yiváš vos.

¿Y cuándo queréš que labre

este lindo bastidor?

Marido, así yiváš vos, maridico, así ỵiváš vos.

${ }^{3}$ Como bien indica AtTias Cancionero (p. 222), era costumbre que la mujer judía acudiera al baño ritual (hb. micvé) ese día para así disponerse a tener relaciones sexuales con su marido el viernes por la noche, es decir, al comienzo del sábado, día principal y santo de la semana judía; de ahí, el cierto pudor de la mujer al no explicitar qué es lo que hace el jueves. Vid., sin embargo, la variante que se indica en la versión B infra, nota 5.

${ }^{4}$ Es decir, salgo a pasear, a dar vueltas haciendo visitas. 
4 Día de miércoles la estiro y la do fierro, marido, así yiváš vos.

¿Y cuándo queréš que labre

este lindo bastidor?

Marido, así ỵiváš vos, maridico, así ỵiváš vos.

5 Día de jueves no vo lo digo, que ya lo sabéš vos ${ }^{5}$, marido, así yiváš vos.

¿Y cuándo queréš que labre

este lindo bastidor?

Marido, así ỵiváš vos, maridico, así viváš vos.

6 Día de viernes amaso y enforno, marido, así viváš vos.

¿Y cuándo queréš que labre

este lindo bastidor?

Marido, así yiváš vos, maridico, así yiváš vos.

7 Día de šaḅat durmo y resfolgo, marido, así yiváš vos.

¿Y cuándo queréš que labre

este lindo bastidor?

Marido, así ỵiváš vos, maridico, así viváš vos.

\section{Versión 1.C}

1 Viernis guiśo y scumparto ${ }^{6}$, šabat maldo y canto.

Merido, así ỵiváš vos, ¿cuándo que vos labri estí lindo bastidor?

2 Alhad duḅlo y guardo los vestidos de šaḅat; lunis lavo la culada y ansí me va la simana ${ }^{7}$.

\footnotetext{
${ }^{5}$ En la fuente editada que he utilizado se indica como variante: «Día de jueves me vo al baño, / marido, así yiváš vos».

${ }^{6}$ Probable variante de escombrar 'limpiar'.

${ }^{7}$ Es decir, así se me pasa la semana.
} 
Marido, así mi yiváš vos, ¿cuándo que vos labri este lindo bastidor?

\section{LA TRANSFORMACIÓN DEL MUNDO AMBIENTE}

Uso para ilustrar este apartado cuatro poemas: los tres primeros presentan casi un repertorio completo de los temas que desarrollan los restantes textos, y el cuarto refleja un aspecto novedoso del mundo ambiente: la incorporación de la mujer al trabajo fuera del hogar.

\section{La nueva Salónica}

El texto procede de las siguientes dos fuentes:

- A: Versión aljamiada publicada en el libro 10 Cantes populares de Sadic y Gaśóś, Cinquena sería (Salónica ca. 1926) pp. 7-8 (Havassy New Texts núm. V) ${ }^{8}$.- En portada: «... 5. Salonico»; cabecera: «Salonico; se canta al son del hermośo foxtrot "Mon París" de la revista El Candid»" .

- B: Versión oral cantada por Alegría Kasorla (Monastir [Bitola], Macedonia 1925 + Israel 1950) y grabada en Rišón leŜiyón (Israel) en 1981 por M. S. Sharon ${ }^{10}$.

Poema de Ŝạic y Gaśóś (seudónimos de Ŝạic ben Neḥamá Gueršón y Mošé ben Abraham Caźés, respectivamente) ${ }^{11}$, que en la versión A consta de tres estrofas -numeradas en romanos- de 8 versos, que van seguidas de sendos estribillos, denominados «Refrén», de 12 versos, el último de los cuales acaba siempre en Salonic; y en la versión B consta de 27 versos en los que resulta difícil rastrear la estructura del original.

El texto de la versión A lo he publicado en mi libro Entre dos (cap. 14 núm. 146) ${ }^{12}$; la versión B es inédita y no la tuve en cuenta en dicho libro.

${ }^{8}$ Para la numeración de los cuadernos compuestos por Ŝạic y Gaśóś me baso en la de Havassy New Texts pp. 24 y 27-31; éste lo fecho según dicha autora pp. 24 y 29.

${ }^{9}$ De las melodías de los poemas publicados por estos autores y de los textos en los que se basan se ocupa Havassy New Texts pp. 12-16 y pp. 93-111, y Apéndice II, respectivamente.

${ }^{10}$ Proyekto Folklor de la Radiodifusión israelí (abrev. PF) 106/6.

${ }^{11}$ Sobre estos dos poetas vid. Havassy New Texts pp. 7-11 y fuentes de notas 20 y 30; y BunIS Voices pp. 282-316; vid. también mi libro Entre dos cap. 10 núm. 82 nota 57.

${ }^{12}$ Vid. la bibliografía que allí recojo sobre ediciones anteriores. A ellas hay que sumar la versión de 18 versos grabada a Esterica Sadikario-Maestro (Salónica), que aparece incluida en el núm. 18 del CD Arboleras vol. 3 de Weich-Sнанак (datos en p. [12] y texto en p. [22] del librito que acompaña al CD). 


\section{Versión 2.A}

1 Hablar vo por muestra civdad, que la llaman «Perla del Eǵé»; yo vos diré pura verdad muchas cośicas a este sujé: hermośo golfo, buen panorama y cada punto troca el clima, tenemos aire de vardar que alevanta el faldar.

Hoy no se ve más los tocados

ni las bragas de tabá ${ }^{14}$.

Los uśos son sacrificados

y las pepitas de sabá ${ }^{15}$.

Los ediques y podias ${ }^{16}$, los mumís ${ }^{17}$ con las oyás ${ }^{18}$ más no brían en las peás ${ }^{19}$. No hay más calvasaráa ${ }^{20}$,

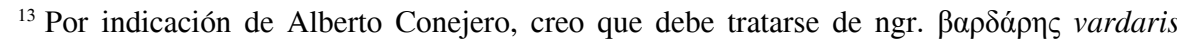
'viento del noroeste, fuerte y frío' y no del nombre del río Vardar que corre cerca de Salónica.

${ }^{14}$ Nehama s.v. brága recoge la expresión bragas de tabaná que traduce 'braies bouffantes en drap grossier que portaient les hommes des classes pauvres', y s.v. tabáko, bragas de tabako 'braies bouffantes en drap très grossier qui s'arrêtaient au genou et que portaient habituellement les tanneurs, les corroyeurs (Elles étaient l'apanage de la classe très pauvre)'; cfr. tc. tabakhane 'tenería'.

${ }^{15}$ Alude a la muy extendida costumbre sefardí de comer pipas en sábado; la última palabra escrita סאבה ‘sábado’ (cfr. hb. שבת šat).

${ }^{16}$ Nehama s.v. pódya explica la palabra 'carré de carton d'une dizaine de centimètres de côté recouvert de taffetas et serti de perles et de filigranes d'or qui termine la partie de la kófya [...] pendant sur le dos des femmes mariées'.

${ }^{17}$ Nehama s.v. mumí (sin dar etimología) lo explica como «cuadrados de gasa bordados con perlas falsas y colgantes de cobre con el que las mujeres en las casas se cubrían el pelo»; y M. Molno Usos (p. 47) dice: «En casa, la mujer casada reemplazaba la cofia por un pañuelo de seda con flores y de color llamativo, el mumi, bordado con perlas falsas que le ocultaba también buena parte del cabello».

${ }^{18}$ Vid. Nehama s.v. oyá.

${ }^{19}$ Entiendo que quiere decir que aquellos pañuelos ya no brillan en las sienes de las mujeres. La última palabra escrita פיאס, cfr. hb. פאה (pl. פאות peot) 'aladares, patillas', que los judíos religiosos se dejan crecer.

${ }^{20}$ Cfr. esp. caravasar; la palabra deriva de tc. kârvansaray, kervansaray 'albergue de caravanas', que NeHAMA s.v. kalvasará explica como 'pétaudière, endroit où il ne règne aucune discipline, où tout est désordre et confusion, où tout le monde se mêle de commander, où l'on entre et d'où sort à toute heure; où chacun agit, crie sans se soucier des voisins'. M. MoLHO «Fouburgos» pp. 7-8 y 11 aporta dos interesantes datos al respecto. Así se llamaban determinados edificios, al estilo de las corralas españolas, de una o dos plantas y con numerosas viviendas, en las que a todo lo largo de la parte que 
caśas con musandará, seš većinas a la sirá ${ }^{21}$.

Ansí vemos todo trocado:

Selanic... en Salonic ${ }^{22}$.

2 Los hombres vestían tumán, las mujeres vestían quiurdí ${ }^{23}$; las caśas, baro con samán, sus construcción era de bagdadí ${ }^{24}$; piedras puntudas eran los jadés, pasaba mucho vestir liḅadés ${ }^{25}$; las barbas sin se arapar, jugaba rolo el parpar.

Las mozas se haćían fiubas, se sarchaban al peinar; los niños, soltucas con jubas ${ }^{26}$ y se vestían sin peinar. No había gramofón, reón-ix ${ }^{27}$ ni telefón, ni orquestra con saxofón,

daba al patio interior había una galería techada, apoyada en postes de madera. Pero además existía un edificio específicamente llamado «patio de la Kalvasará», situado en el barrio de los carniceros llamado Islaḥané (cfr. tc. islahane 'reformatorio'); vid. al respecto SAPORTA Torre p. 216. Por lo que se dice en el verso siguiente, en el que se habla de forma generalizada, he supuesto que aquí no se refiere al mencionado edificio sino al tipo de casas, por lo que he optado por escribirlo con minúscula.

${ }^{21}$ Cfr. tc. sira 'fila; en fila'; Nehama s.v. sirá, amén de indicar también el étimo ngr. $\sigma \varepsilon \imath \rho \alpha ́$ sirá -palabra oxítona, que es la que aquí conviene por la rima-, traduce la expresión a la sira 'l'un après l'autre, en rang d'oignons'; y por su parte M. MoLHo en su manuscrito inédito sobre Turquismos explica la expresión hablar a la sirá, que es la que aquí se intuye, como 'hablar sin interrupción'; entiendo, pues, que lo que hacen las mujeres es parlotear todas a la vez, quitándose la palabra unas a otras.

${ }^{22}$ Cfr. tc. Selânik y fr. Salonique.

${ }^{23}$ Cfr. tc. kürdî ‘kurdo, del Kurdistán', palabra que Nehama s.v. kyurdí explica como 'manteau que les femmes orientales, juives comme musulmanes, mettaient par dessus leurs vêtements, en guise de surtout, quand elles sortaient dans la rue'.

${ }^{24}$ Cfr. tc. bağdadî, que NeHAMA s.v. bagdadí explica como 'construction légère faite de lattes de bois et de plâtre; lattis'.

${ }^{25}$ Es decir, se daba mucha importancia, se presumía de vestir tal prenda, que por error está escrita liḅadós.

${ }^{26}$ NeHAMA recoge $\breve{g u ́ b a ~ ' b a t a ~ d e ~ c a s a ; ~ b l u s a ~ d e ~ t r a b a j o ', ~ y ~ g ̆ u b e ́ ~(t c . ~ c u ̈ p p e, ~ c u ̈ b b e), ~ q u e ~ t r a d u c e ~}$ 'sorte de toge, de vêtement de dessin en tissu mince pour homme, soutane'; cfr. esp. aljuba.

${ }^{27}$ Escrito ריאון־איקס, quizá la primera palabra se trate de un error gráfico por ראיון rayón, cfr. fr. rayon Ixe 'rayos equis'. 
ni los bailes exantric, ni el tram con electric, no se vía aciduric ${ }^{28}$. Agora es todo trocado, en moderno Salonic.

3 Mos quiis̀imos civiliźar en tomando todo a revés; el luso, la moda biźar ${ }^{29}$ es el progreso de la mancebez.

Tenemos fraguas hechas con betón, musiú con gantes, fiongos y bastón; las niñas, con sus volupté, exitan con sus decolté.

Hoy hay bulevares y plazas

que alegran [el] corazón; las niñas parecen descalzas y arapar a la garzón ${ }^{30}$.

Vemos los otós corer, mos salpican sin quierer, polvorina en el barer.

Salonico se trocó después que se chamušcó ${ }^{31}$; ma de lodos él no mancó. Aínda sos muy incompleto, ¡oh, moderno Salonic!

\section{Versión 2.B}

Yo vos diré por la verdad por los uśos de muestra civdad.

Tenemos aire de vardar que s'alevanta el faldar.

5 Piedras pontudas eran los jadés pasaba mucho vistir liḅadé.

\footnotetext{
${ }^{28}$ Escrito אסידוריק 'ácido úrico'; lo que quiere decir irónicamente es que nadie padecía de gota.

${ }^{29}$ Rectifico mi anterior lectura beśar por biźar 'raro, curioso, bizarro' que se ajusta más al texto. Agradezco a Rivka Havassy tal precisión.

${ }^{30}$ Es decir, con el pelo cortado «a lo garzón».

${ }^{31}$ Es decir, tras el terrible incendio que el 18 de agosto de 1917 destruyó el nucleo antiguo de la ciudad.
} 


\author{
¡A $\mathrm{A} !$, hoy no se ve los ducados \\ ni las bragas de tabac; \\ los uśos son sacrificados, \\ 10 las pepitas de šaḅat. \\ Vemos los otós correr, \\ mos sarpican sin querer, \\ polvorina en el barrer. \\ ¡A \\ 15 el moderno de Salonic. \\ Non hay más caśas saray, \\ caśas con musandará, \\ seš vićinas a la sirá. \\ Las niñas se haćían fiuḅa, \\ 20 se sarchaban al pinar; \\ los hombres, soltucas con jubbas, \\ se vestían sin peinar. \\ Non había gramofón, \\ varones ${ }^{32}$ san instrucción, \\ 25 ni los bailes exantrís ${ }^{33}$ \\ ni el tram sin aletric, \\ no se vía aciduric ${ }^{34}$.
}

\title{
3. Ubi est Salónica
}

El texto procede de la siguiente fuente única:

- Versión aljamiada publicada en el libro Los cantes populares de Sadic y Gaśóś (Salónica abril 1935: Biḅlioteca del Rayo, Edición del Rayo, Tip. Populara) p. [3] (Havassy New Texts núm. XI).- En portada: «En fablando de París»; cabecera: «Se canta al son del fox "En parlant un peu de Paris"» (en caracteres latinos).

Poema de Ŝạic y Gaśóś, del que se ocupa Havassy New Texts (pp. 68-72); y también lo publica Bunis Voices (pp. 289-290).

Consta de tres estrofas denominadas «Cuplé»-numeradas en arábigos- de 9 versos, que van seguidas de sendos estribillos, denominados «Refrén» e igualmente numerados en arábigos, de 10 versos.

\footnotetext{
${ }^{32}$ Parece decir valones.

${ }^{33}$ El verso se repite en el canto.

${ }^{34} \mathrm{Al}$ terminar de cantar y tras una breve pausa la informante repite el v. 5 igual que antes y el v. 6 con cambios: «habiya muncho vestir liḅadés».
} 
1 Con el tiempo y progreso

Salonico se trocó;

de aquel plaćer imenso

su brio se aflacó;

él devino evropeo,

no hay más el repotreo,

lo viejo pasó

y se replazó,

ma la criś mos alcanzó.

¿Lo qué fue el buen Salonic

sin el mal que hoy es cronic?

Sí había tiñas,

ma lo de las niñas

no era quiepaśilic;

se caśaban chicas de boy ${ }^{35}$,

no había lo que hay hoy:

hijicas despertas,

diablas, coquetas

con la eleganza, el čhic.

2 No había pudriduras

ni dancingues ni bailar;

las mujeres eran puras

sin los mušos encalar ${ }^{36}$,

como chocas con los hijos ${ }^{37}$,

arastando por cortijos.

Comer sin pensar,

quiebapes asar,

pan en caśa amasar.

Atrás tiempo en Salonic, con fortuna y ferahlic,

gente se vestían

y se mantenían

sólo con un altelic.

Hoy no hay «medán» ni «capán», ma platías, güertas, sin pan; despareció Rogos ${ }^{38}$,

\footnotetext{
${ }^{35}$ Es decir, muy jóvenes.

${ }^{36}$ Es decir, sin pintarse los labios.

${ }^{37}$ Es decir, como gallinas cluecas con su camada; vid. tb. NeHAMA s.v. čóka.

${ }^{38}$ Nombre de un barrio de Salónica.
} 


\author{
marcas a los bogos \\ todos tienen a bolĝelic ${ }^{39}$. \\ 3 No había los engaños: \\ la palabra de honor \\ era mejor de notarios; \\ ¡qué ventura, qué bonhor!: \\ se escapaban los tratos ${ }^{40}$ \\ sin papel, sin abocatos; \\ tratar con hablar ${ }^{41}$, \\ todo regular, \\ después pranzos y bailar. \\ Hoy hay radio en Salonic, \\ telefón es otomatic; \\ coquetas vitrinas, \\ caras de mongrinas ${ }^{42}$, \\ esto hiźo la tecnic. \\ Hay los que tenían quiemer ${ }^{43}$, \\ hoy no tienen para comer; \\ hay mucho čhomaǵe, \\ piedrer el coraǵe. \\ Esto ya devino panic.
}

\title{
4. Tiempos trocados
}

El texto procede de la siguiente fuente única:

- Versión probablemente aljamiada publicada en el periódico La Vara de Nueva York hacia 1927.

\footnotetext{
${ }^{39}$ Entiendo que el sentido de los dos versos es que todos tienen en abundancia (a bolgelic) marcas (quizá con el sentido de 'remiendos') en los fondillos de los pantalones (bogos). NeHAMA s.v. bolčelík recoge tener bolčelik que traduce 'nager dans l'abondance', que no parece ser la adecuada en nuestro caso.

${ }^{40}$ Es decir, se cerraban los negocios, aunque por lo que se dice luego sobre banquetes y bailes, también podría entenderse como referido a los acuerdos matrimoniales.

${ }^{41}$ Es decir, los negocios se cerraban hablando.

${ }^{42}$ Nehama s.v. kára recoge la expresión kara de mungrina que traduce 'visage maussade, renfrogné [...]'.

${ }^{43}$ Tc. kemer 'cinturón', palabra de la que Nehama s.v. kyemér precisa 'bourse suspendue à la ceinture, comme c'était jadis l'usage en Orient', y M. MoLHo Turquismos 'Cinturón donde se guardaba antaño el dinero de oro y plata'.
} 
Poema firmado por el seudónimo de «Empostemado», el cual me ha llegado en letras latinas por la edición (mala) que de él hicieron Savariego - SánchezBoudy Poemas de 'La Vara' (pp. 72-73), en el que no hacen ninguna precisión sobre el número y año del periódico en el que apareció. Lo titulan Noventa años antes, título que no sé si es de los editores o del original.

Consta de 12 estrofas de versos con rima $a b a b$ en ocasiones largos.

1 Noventa años antes, cuando mi padre era mancebo, cantaba armoniośos cantes, ma sin un feo vierbo.

2 Hoy, cuando el hijo canta cantigas de amores, su... yoz más y más alevanta y en su tripa hay munchos dañadores.

3 Noventa años antes las madamas vestían muy modestamente; eran buenas de corazón, buenas de almas, a sus maridos amaban sinceramente.

4 Hoy las mujeres enteramente trocaron, visten vestimentas muy lusosas; de más en más ellas se alterearon, si no les daš moneda, devienen mutrośas.

5 Noventa años antes las hijicas todos sus cuerpos se cubrían; sea de grandes como chicas ni mismo sus calzados no se les vían.

6 Hoy son a la contra: las hermośas sus cuerpos cubren muy poco; muestran ginollos y otras cośas y a cada mancebo rindiendo poco ${ }^{44}$.

7 Antes noventa años se sabía que la que nacía hija, hija quedaba; cortaduras de cabellos no ex́istía ni ninguna hija no se arapaba.

8 Hoy las cośas trocaron enteramente: las hijas se arapan como los hombres,

${ }^{44}$ Quizá quiere decir que a cada chico que se les acerca le dan algo. 
quien es hij́a no se aparta de enfrente ${ }^{45}$, lo que les manca es sólo... los nombres ${ }^{46}$.

9 Antes noventa años los genitores se ocupaban por sus hijas de caśar, las metían en manos de coredores, lo que ellos dećían no se debía refuśar.

10 Hoy no hay coredores ni caśamenteros, las hijas a sus compaños apañan; ya es bueno cuando salen sinceros, ma, ¿cuálo haćer cuando las engañan?

11 Antes noventa años había iñoranza, que muncha estupiditá ex́istía; ma de dinguna cośa no había mancanza: amor, sinceridad, honestidad se vía.

12 Hoy en este siécolo de civilización, que nuevos inventos inventaron, todo lo bueno tuvo disparición, hijos y hij́as enteramente trocaron.

\section{Mujeres trabajadoras}

El texto procede de la siguiente fuente única:

- Versión aljamiada publicada en el libro de Saḍic y Gaśós, 12 Cantes populares, Cuarta sería (Salónica 1925: Edición de La Vara) p. 4 (Havassy New Texts núm. IV).-En portada: «... 2) La conquerencia femenina ("Rośita”)»; cabecera: "La conquerencia femenina; se canta al son de "Rośita"».

Poema inédito.

Consta de tres estrofas -numeradas en arábigos excepto la primera- de 14 versos largos y cortos, seguidas de sendos «Refrén», igualmente numerados, de 4 versos largos de rima zejelesca $A A A B$, rimando el verso de vuelta en -ar.

1 Con dulces versos hoy vos quiería cantar por dećir lo que penso sin me espantar.

Veo que el hermośo sexo

haće progreso

de respectar.

\footnotetext{
${ }^{45}$ Entiendo que quiere decir que las mujeres no ceden terreno, que presentan cara.

${ }^{46}$ Lo que les falta a las mujeres es una de dos: o el nombre de hombre o que les pongan nombres masculinos.
} 
En los burós y grutas las vemos en pies, sin ellas, hombres, non valemos un dediez; y en cualunque brančh de hecho, en el comercho $\mathrm{y}$ ande quiés ${ }^{47}$ hay dactilós, vandośas y contaḅles. Haće plaćer al sentirlas hablar, al servir al cliente son muy agradables; al hombre percuran de igualar.

Hoy las mujeres no se contan por medallas ${ }^{48}$ : ande las quiés bušcar, ahí miśmo las fallas.

Para menaje valen y son balabayas, esforzos haćen para se emancipar. [Múśica] ${ }^{49}$.

2 Se van las niñas como hombres al labor, blondas, haninas ${ }^{50} \mathrm{y}$ morenas con sabor; y la mujer ansí hoy gana, non se condana, topa favor. Se ve la que es šastra, la que es brodóś; siempre toman el tram y no la baladóś, y angaǵé siempre caminan cuando combinan a tres, a dos ${ }^{51}$.

Soldo a soldo la pará ajuntan para recamos o la broderí, con antredós ${ }^{52}$ y cordelas las apuntan, muchas las gastan en parfumerí.

Para vendersen van las niñas enlusadas, que por topar marido ellas son forzadas y sin la dota se sienten embarazadas, al niño bušcan y sin lo pueder topar. [Múśica.]

\footnotetext{
${ }^{47}$ Es decir, donde quieras.

${ }^{48}$ Entiendo que quiere decir que no se les caen los anillos.

${ }^{49}$ Entiendo que con esta indicación se está dando pie a la ejecución de un solo musical.

${ }^{50}$ Quizá la palabra venga aquí para adjetivar a las rubias (blondas), es decir, 'hermosas rubias', en cuyo caso habría que eliminar la coma.

${ }^{51}$ Es decir, cuando coinciden tres o dos.

${ }^{52}$ La palabra está escrita antredés, que no sé si es un error gráfico o viene a indicar una mayor proximidad al étimo francés.
} 
3 Los niños, fieros, se lo saben contener, una mujer non saben ellos mantener.

Los ves telipuli en gruta, va hey pregunta ${ }^{53}$ : ¿hay disponer? ${ }^{54}$

Vente cutís vaćíos es sus capital, llamando van clientes siempre al portal ${ }^{55}$. El coredor, que tomó güesmo sin saber miśmo si hay total, demarčhes haćen ${ }^{56}$, también entrevistas, a la niña la haćen expośar; la precian por basmal o bien batistas ${ }^{57}$, da godra dota para se caśar.

Ansí la niña que al niño hoy conquere la noche y el día cale se apure.

Que sienta mi consejo y que se percure ${ }^{58}$, modestamente debe bušcarse su par.

\section{LAS NUEVAS MODAS Y LOS LUJOS}

Ilustran este apartado los siguientes ocho textos.

\section{La suerte de Adán}

El texto procede de la siguiente fuente única:

- Versión en letras latinas publicada en el libro de Abraham A. Cappon, Poesías, Tomo segundo ... (Sarajevo 1922) pp. 22-24.- Cabecera e Índice (p. [VIII]): La moda y la culebra.

${ }^{53}$ No sé quién es el sujeto del $v a$ inicial, si «tú, lector» o el joven al que se está criticando.

${ }^{54}$ Que no entiendo bien qué quiere decir, pero, si está hablando el joven, quizá se trate de una fórmula para preguntar si hay trabajo.

${ }^{55}$ Que no sé si quiere decir que desde la entrada de las tiendas llaman a los posibles clientes para que entren a comprar o que van vendiendo de casa en casa.

${ }^{56}$ Tampoco tengo claro quién es el sujeto de este verbo en plural, si los casamenteros o los jóvenes; así pues no estoy segura de mi puntuación.

${ }^{57}$ La primera palabra (tc. basma) indica un tipo de tela estampada de baja calidad, en tanto que la segunda, la batista, se trata de una tela mucho más fina; es decir, que valoran a la mujer por la calidad del ajuar que tiene preparado.

${ }^{58}$ Es decir, que se esfuerce. 
Poema en letras latinas de Abraham Aharón Cappon, editado también (con errores) por Elazar Romancero (pp. 174-177 y 338), quien fecha su composición en ca. 1890.

Consta de 23 estrofas numeradas, formadas por aleluyas emparejadas. Respeto mayoritariamente la grafía del original, pero son mías la acentuación y la puntuación.

1 Adam, Adam, primer creado, ¿por qué te muestras tan ansiado?

Tú tuviste buen reposo y viviste biendichoso.

2 Tus días fueron venturosos y sin suspiros dolorosos, sin fatigas por riqueza, sin miseria, sin pobreza.

3 El Creador, muy poderoso, te hizo hombre biendichoso, dándote sobre la tierra a Ḥavá por compañera.

4 La compañera de tus días sacada fue de tus costillas; tú un solo hueso daste por la linda que amaste.

5 Te fue esposa bienquerida y siempre alegró tu vida; ella siempre te amaba y tu orden respetaba.

6 Ansí con ella bien viviste a desreposos no tuviste; no tuviste los dolores de los lujos malhechores.

7 Havá tu vida adulzaba y nunca ella se quejaba; a los corsos no salía, modas, lujos no quería.

$8 \mathrm{Ni}$ a los bailes se andaba, ni máscaras te demandaba, ni cordelas en los trajes ni chapeos (sombreros) con plumajes. 
9 Ni sedas finas ni cordones para lujosas guarniciones, ni plastrón con botonicos, ni calzados estrechicos.

10 No anteojos colgadicos y no corsés apretadicos, ni vestidos demudados de colores desmayados.

11 No frecuentaba los conciertos, ni los teatros ni los huertos; ni binóculos llevaba, ni monóculos buscaba.

12 Son ya de veras estas cosas para la vida provechosas; empero las demasías causan males y mancillas.

13 En estos tiempos hay esposas que sin medida son lujosas. No hubiera: hay maridos por las modas destruidos.

14 Adam, tú debes consolarte y con tu parte alegrarte, porque modas tú no viste y dolores no tuviste.

15 De tus costillas una diste por la mujer que adquiriste; muchos dan en estos días casi todas sus costillas.

$16 \mathrm{Si}$ gastan todos sus haberes, no se contentan sus mujeres, que, por modas sin medida, truecan todo en la vida.

17 Sus huesos todos, si darían, sus damas más demandarían; si rehúsa el esposo, para él no hay reposo.

18 Adam, Adam, primer creado, tú fueste bienaventurado: 
de dormir te despertaste ${ }^{59}$, con Havá te alegraste.

19 Agora hay quien se despierta y corre presto a la puerta; si cerrada estaría, la ventana saltaría.

20 Adam, Adam, primer creado, tú fueste bienaventurado, con Havá muy bien viviste y dolores no tuviste.

21 Si fue tu vida angustiosa por la culebra desastrosa, más que ella mordedora es la moda dañadora.

22 Aquella sierpe venenosa te dio la fruta deliciosa; mas agora hay maridos por las modas destruidos.

23 La culebra si darías y la moda tomarías, muchos hombres trocarían y ganancia te darían ${ }^{60}$.

\section{Las modas de Francia}

El texto procede de la siguiente fuente única:

- Versión aljamiada en el manuscrito de Ya‘acob Hazán (Rodas, finales del siglo XVIII) f. $37 r^{61}$.

Canción tradicional inédita que consta de 12 estrofas: las tres primeras son aleluyas emparejadas y parecen pertenecer a otro texto; y las nueve restantes son cuartetas con tendencia a rima asonante en los pares.

1 Da la ỵuelta, se asenta en la chisé con chibuc de yurmeší,

${ }^{59}$ Alude al pasaje de Génesis 2:21-22, en el que Dios infunde un sopor en Adán para extraerle la costilla de la que forma a la mujer.

${ }^{60}$ Es decir, se quedarían con la culebra y encima te darían dinero.

${ }^{61}$ Fecho el texto según las precisiones de Armistead - Silverman 3 Calas (p. 18 núm. 40 y p. 20), quienes lo atribuyen a la mano I del manuscrito. 
todo jamliques ${ }^{62}$, ¡vah!!, la mujer de ariques ${ }^{63}$.

2 Da la yuelta, se va para la cordón ${ }^{64}$, la condona con el condón ${ }^{65}$; todo jamleado ${ }^{66}$, ¡vạ!!, la madama a'lado.

3 Da la ỵuelta, se v'a la cavané, la cavé, la narguilé; todo comfiado, músicas a'lado.

4 Las muchachas d'agora se visten y se afeitan; horas de tadre viene ${ }^{67}$, se asentan en la puerta.

5 Los mancebos pasan, amostran las tetas; ¡vay de los mancebos!, que se van quemando.

6 Las muchachas d'agora se visten de amarío, soltan a los maridos se van con los amigos.

7 Agora no pasan zapatos de Serbía, sino lo que pasa, ¡vay!, potín de Franquía.

8 Potín de Franquía para una vestida ${ }^{68}$;

${ }^{62}$ Nehama s.v. ğamlík (cfr. tc. camlık 'acristalado') traduce 'cloison vitrée', es decir, cancel de vidrio que sirve para dividir una habitación.

${ }^{63}$ Escrito אריקיס, que no sé qué es ni si se trata de un nombre propio.

${ }^{64}$ Pero Nehama s.v. kordón señala la palabra como masculina; así que ignoro hacia dónde se va nuestro sujeto.

${ }^{65}$ En ngr. existe кокóva 'dama, señora' (tb. irónicamente 'prostituta'); quizá se trate aquí de un error gráfico por dicha palabra y una invención léxica -cocón- para referirse al marido; es decir, el marido y la mujer o el señor y la señora.

${ }^{66}$ Tc. camla- 'acristalar', caml ' 'acristalado'; vid. nota 62 supra.

${ }^{67}$ Es decir, cuando llega el atardecer.

${ }^{68}$ Es decir, para una sola postura. 
¡guay de los maridos!, que se queman en vida.

9 Agora no pasan ropas telías ${ }^{69}$, sino lo que pasa, ¡vay!, ropas de Franquía.

10 Ropas de Franquía para una vis̀ita; ¡vay de padre, madre!, que se queman en vida.

11 Los mancebos d'agora son del burino alto ${ }^{70}$, toman el contado para cortar tacos de paño ${ }^{71}$.

12 Los mancebos d'agora tienen el burnú alto ${ }^{72}$, toman el contado, se haćen unos patos ${ }^{73}$.

\section{7bis. Los afeminados de antaño}

El texto procede de la siguiente fuente única:

- Versión aljamiada publicada en el libro de Šelomó Šalem, La gavilla La Gerbe (el segundo título en caracteres latinos) [Salónica ca. 1900] pp. 22-23. Cabecera e Índice, denominado Tábula de materias (p. [41]): Esto hay en el mundo.

Poema inédito de Šelomó Šalem, que consta de 31 aleluyas (= 62 versos) que no separo, numerando los versos. El texto tiene de singular el abordar un tema totalmente novedoso: mostrar cómo la pasión por las modas en el vestir hace que, al menos en apariencia (sin que sepamos qué hay detrás de tal apariencia), algunos jóvenes parezcan chicas.

${ }^{69}$ Es decir, vestidos bordados en plata y oro, según la antigua usanza turca; cfr. tc. telli.

${ }^{70} \mathrm{La}$ construcción es paralela a la que vemos más abajo (vid. nota 72 infra). Debemos entender, pues, la palabra burino como tc. burun 'nariz', para decir que los chicos de por entonces se lo tenían muy creído, iban con la nariz levantada.

${ }^{71}$ Parece decir que los jóvenes usan el dinero de las dotes para algo tan absurdo como hacerse tacones (vid. NeHAMA s.v. táko) de paño.

${ }^{72}$ Cfr. tc. burun 'nariz'; es decir, que van con la nariz levantada. Comento una construcción parecida en nota 70 supra.

${ }^{73}$ Nehama s.v. páto recoge la expresión fazerse un pato que traduce 's' enorgueillir des éloges, des flatteries dont on est comblé, se rengorger'. 
1 Ayer era con un hombre -después vos diré su nombre-, le contaba una cośa grande y maraviośa.

5 Con atanción esto meldad. -Es increible, ma verdad-, -dećia yo a mi compañoesta moda de hogaño. Yo conozco un muchacho,

10 no tiene inda mostacho, bastante inteliĝente, vestido corectamente, entero un figurino $\mathrm{y}$ de facha muy belino;

15 muevamente franqueado y..., mejor quedar callado.

Este muchachico miśmo emprestó del feminiśmo todas sus coqueterías.

20 No te burles ni te rías, ni tengas cabeza todra. Hay un otro con la pudr[a] que blanquea las sus caras por taparse ciertas taras.

25 Hay otros de entre ellos empretecen sus cabellos por mostrarsen que son chicos ¡y son todos muchachicos!... Lo que topo revoltante,

30 miśmo tiempo diśgustante, es el hecho de el corsé...; manías y más cośas yo sé que un otro hay que lleva. ¡Es cośa que se reeva¡-.

35 -¡Ma es cośa imposible, miśmo tiempo increible! -mi amigo me replica-: Esto haće Rahelica, siendo ella es una niña; 
40 ma, ¿un niño? ¡Me indiña...!-.

-Callado, te rogo, Nunú ${ }^{74}$,

que por el hecho del turnú

no hablí aínda nada.

Si haćes la caminada

45 tú la tadre por el molo,

estáte mirando solo

el que camina de lado

y acércate al lado;

con maneras o resiento

50 mete mano al as...to [= asiento]

y verás que es ḥandrajos

hechos con forma de tajos

que tienen de cada parte

metidos con mucho arte;

55 y a estos, de la moda, no les manca que la coda.

Yo los puedría escoǵer,

por semejar una mujer...-.

Aquí hago un esforzo,

60 interumpo mi discurso.

Dejo para la otra vez

hablar de esta mancebez.

\section{Pasión por las modas}

El texto procede de la siguiente fuente única:

- Versión aljamiada publicada en el libro de Alexandro Pérez̧, Buqueto de cantes compośados por - y Las muevas complas del felec ([Salónica ca. 1920]: Edición Čharló; Estamparía Beźés) (Baecs 223) pp. 12-13.- En portada: «... 9. El mal de la moda; cabecera: El mal de la moda (cante satírico al son de "La balladera")».

Poema inédito de Alexandro Pérez̧, que consta de 4 estrofas de 5 versos de rima $a a b b a$, seguidos de sendos «Refrén» de siete versos y rima $a b a b c c c$ en el primero y $a b a b c c b$ en los tres restantes.

1 El mal de la moda trespasó:

la saloniciana alcanzó

\footnotetext{
${ }^{74}$ La palabra en letra cuadrada y los dos vavs vocalizados con un punto dentro; de ello deduzco que se trata del nombre propio del interlocutor, anunciado por el poeta en v. 2.
} 
la americana

y la pariśiana

y puede ser miśmo las pasó.

La dalavera

de la niña del dor...

non se tolera,

calladez es mejor.

Te sabe inventar

ciento y un mantar

cuando se quiere... contentar.

2 Todas son celośas al vestir

y ninguna puede reśistir;

por la moda mueva

la mujer manceba

sabe pelear y no sentir.

La dalavera

la conocen muy bien

la servidera,

la madama también;

con el más que ḥaber...

o bien con sus saber

gastan puñados de a cien.

3 Apena mos mandan de París

modeles de muevos antarís,

muchas empiegadas

gastan sus meśadas

y se empeñan fin la... nariz.

Para haćersen

un vestido bien čhic

saben vendersen

y tener ališic ${ }^{75}$

con niños con bastón,

con Petro, con Gastón ${ }^{76}$,

les plaće mucho carišic...

\footnotetext{
${ }^{75}$ Perez - Pimienta s.v. alishik (cfr. tc. allşı) traducen 'relaciones sociales o comerciales'; es decir 'tener trato' con los chicos que se mencionan luego, que por el bastón y los nombres parecen pertenecer a la nueva ola y quizá además sean jóvenes con dinero.

${ }^{76}$ Nombres no judíos, que probablemente llevan judíos «a la moderna»; pero también cabe pensar (sobre todo por el nombre de Petro) que se esté aludiendo al trato de las chicas con cristianos.
} 
4 Póberos maridos que tienen compañas de vida que quieren gastar la moneda por ropas de seda hechas a las modas que vienen.

Abrid los ojos mancebicos del dor; vestid entojos ${ }^{77}$... porque es mucho źor tener una mujer que siempre va quierer mercar el vestido mejor.

\section{Los pobres y la moda}

El texto procede de la siguiente fuente única:

- Versión oral cantada por Suśán Avigdor (Constantinopla ca. 1910 + Israel 1949) y grabada en Yafo (Israel) en 1978 por Moshe Shaul ${ }^{78}$.

Canción tradicional inédita, que consta de 3 cuartetas de rima en los pares. La fecho por aproximación en ca. 1920.

1 La moda cale haćer aunque semos probes; la colana ${ }^{79}$ que llevo yo no saben que es de cobre.

2 El calzado que llevo yo lo tengo burracado y, si alguno demandará, diles que tengo callo.

3 Bonjur, bonsuar, ya m'ambeźí y a bailar m'ambeźo; demuaśeles angajar, meśmo darles un beśo.

\footnotetext{
${ }^{77}$ Es decir, poneos gafas.

${ }^{78} \mathrm{PF} 08 / 2$.

79 Tc. sing. kolan 'cinturón, faja', pero aquí parece tener el sentido de 'cadena, colgante', que también recogen PEREZ - PIMIENTA Diksionario s.v. kolana, sin indicar etimología y como palabra diferente de kolan.
} 


\section{Achuchado por la moda}

El texto procede de la siguiente fuente única:

- Versión oral cantada por Lunchica Attias (Sarajevo, Yugoslavia 1913 + Israel 1949) y grabada en Jerusalén en 1989 por Moshe Shaul ${ }^{80}$.

Canción tradicional inédita, que consta de 10 cuartetas con rima en los pares. La fecho por aproximación en ca. 1920. Otra versión de 8 estrofas (faltan las 4 y 6 infra), grabada a Alegra y Simo Calderón (Monastir [Bitola], Macedonia) por Weich-Shahak, la publica la propia colectora en su CD Arboleras vol. 3 (núm. 11, p. [19], con datos en p. [10]), donde la titula Un padre en apuros.

1 Yo so un buen crayidor ${ }^{81}$, yo un viejo padre

y amo a la mi mujer, de me ${ }^{82}$ hijos madre.

2 Y amo al me hijo junto con la hija, que cuando me durmo bueno m'acobijáan.

3 Al hijico le merquí tutó ${ }^{83}$ por la calli sólo, mis hermanos, para que non guayi.

4 Le merquí culetu, čhimís, vistidico, sólo que'sté lindo cuando lo ve el amigo.

${ }^{80}$ PF 320/5.

${ }^{81}$ Eso es lo que oigo; al menos, la informante empieza diciendo cra, se corta y farfulla. Quizá quiera decir, por lo que luego arguye el protagonista, que es un buen criador, un buen padre.

${ }^{82}$ Es decir, de mis.

${ }^{83}$ Perez - Pimienta s.v. tuto traducen 'orinal' (fr. tout 'todo' + tôt 'temprano' ?), que, teniendo en cuenta que el por que sigue puede ser también para, quizá quiera decir que se lo compró para ponerle a hacer pis cuando salga a la calle. Cfr. tb. fr. toton 'peonza'; y fr. toutou 'perro, guauguau' en el lenguaje infantil; no creo que aquí la palabra esté en relación con tutu 'faldilla de bailarina', aunque vaya usted a saber. Por su parte en la versión de Wегсн-Sнанак se dice un menos conflictivo todo; ello induciría a pensar que en el caso de mi versión pudiera tratarse de it. tútto 'todo', lo que, sin embargo, no me parece probable tanto por la acentuación oxítona de la palabra en mi texto como porque en las estrofas siguientes el complaciente progenitor y esposo siempre compra a sus familiares cosas concretas. 
$5 \quad[\ldots]^{84}$ y puder a la hija merco; con ella es gasti, ¡sí la llevi el güerco!

6 Ya la deǰo, creermi, y que se enamori, sólo, mis hermanos, para que non llori.

7 A la mujer le merquí vistidus di seda y escarpicas blancas untadas con creda.

8 Mi calía mercarli caputos d'invierno, se non ya me dići que no so moderno.

$9 \mathrm{Y}$ ansina vieni qui llevo handrajos y en caśa como pan seco con ajo.

10 Siempre estó muy roto y muy ar'mendado; s'avergüenza la mujer de me ver al lado.

\section{Las viejas y la moda}

El texto procede de la siguiente fuente única:

- Versión aljamiada publicada en el libro Los cantes de La Gata (Salónica agosto 1927: Edición de La Gata) p. 12.- En portada: «... 13. La vieja y la moda ("Crémete")»; cabecera: «La vieja y la moda, se canta al son del alegre fox-trot "Crémete..." 85

Poema inédito firmado con el seudónimo «El paitán de La Gata». pudra.

${ }^{84}$ Lo que oigo suena como šmi(n)ca; en la versión de WeIch-ShahaK el verso es al y chic y

${ }^{85}$ Conejero en su futuro artículo «Cantes satíricos» (Apéndice núm. 3, nota 44) identifica

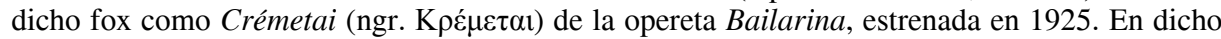
artículo CONEJERo editará también, amén de este texto, mis núms. 15 Foxtrot, 18 Mal de los bailes y 23 Señoritos. Agradezco al autor el haberme dejado consultar su original inédito. 
Consta de 2 estrofas, llamadas «Cuplé» y numeradas en arábigos, formadas de dos grupos de cinco versos y rima $a a b b b$ y rematadas por un verso igual en las dos estrofas, seguidas de sendos «Refrén», también numerados en arábigos, que constan de dos grupos de 4 versos que son aleluyas emparejadas.

1 El ver següir la moda con la criśa mos provoca y la riśa; vemos a tía Malcá, aferada de macá ${ }^{86}$, vestir orejales con grande ḥalcá.

Quiere también y vestido delgado en las carnes apegado por dejar el puerpo ver, o... por respirar aver, o bien por se atirar algún ḥaber ${ }^{87}$.

Conbineźón con garneźón la moda es de la seśón.

Luso y moda quieren alcanzar, mozas y viejas se quieren lanzar; todos deśean muevas modas y plaćer, solo con esto se pueden satisfaćer.

A sus echar, a sus alevantar, ellas non quedan nunca de gastar; para la šastra, el cuafur, la manicur todas saben vender, tambien y sus chicur ${ }^{88}$.

2 Combina que al ver alguna vieja

mos parece y conseja:

chapeico san-rival, vestidico y de vual, ramplazando el quiurdí, la pištamal.

Se fardan bien y se meten al tiro ${ }^{89}$ y al verlas yo suspiro: cuafada a la garzón, vestida dernier-fasón y con un caré que pasa el pezón...

\footnotetext{
${ }^{86}$ La palabra escrita מאקה (cfr. hb. מכה 'plaga'); es decir, contagiada por la plaga de la moda.

${ }^{87}$ Escrito חאב'ר (cfr. hb. חבר); es decir, para buscarse algún novio.

${ }^{88}$ Nehama s.v. čikúr traduce 'lien de la culotte, cordon qui mantien la culotte'; cfr. tc. çukur 'agujero, cavidad' y tb. slang 'nalgas, posaderas'.

${ }^{89}$ Es decir, se ponen de punta en blanco, se acicalan.
} 
Conḅineźón con garneźón la moda es de la seśón.

El hombre solo tiene a sufrir: mujer y hija lo saben munĝir; para el luso gastan toda la pará que con regreto la versa el fucará. Condurias vedres y calzas čher ${ }^{90}$, que sean finas, miśmo sin teǰer, quiere Malcá, Sunḥula y también Júlí ${ }^{91}$, que solamente al verlas dićes: ¡ya yolí!

\section{Los jóvenes pretenciosos}

El texto procede de la siguiente fuente única:

- Versión aljamiada publicada en el periódico de Salónica Acción (2) 10/2588 (1938) p. 3c.-Cabecera general: «Muestros regalos y las complas de Purim»; precede al texto: «Se acodren de los hijicos» ${ }^{92}$ (Baecs $257 \mathrm{c}$ ).

Copla inédita y anónima, que consta de 4 cuartetas de rima zejelesca aaab, con vuelta mayoritaria en -ar.

1 Quien ve hoy los mancebicos, sea probes como ricos, los grandes como los chicos todos tienen pretansión.

2 Entornados de pirianas ${ }^{93}$, no controlan sus hermanas, muchos quitan almoranas porque gastan sin pensar.

3 Son esclavos de la moda, lo más son peros de boda ${ }^{94}$; toman todo por la coda ${ }^{95}$ si salen a espośar.

\footnotetext{
${ }^{90}$ Que amén de fr. cher 'caro' puede tratarse del nombre de una marca de medias.

${ }^{91}$ Los dos primeros son nombres tradicionales; no así el tercero a la francesa (Julie).

${ }^{92}$ Inicio de la copla clásica de Purim El daledale de Purim, de Sa ‘adí Haleví (Baecs 79b y ss.).

${ }^{93}$ Nehama s.v. piryán y sin indicar etimología (cfr. tc. pir, pl. pirân 'joven marido, amo, patrón' ?) traduce 'amant, amoureux [...]', es decir, novias de las de ahora.

${ }^{94}$ Así se llamaba a los que, con el fin de comer y beber gratis, se colaban en las bodas sin haber sido invitados.

${ }^{95}$ Que quizá quiera decir como esp. 'coger con pinzas'.
} 
4 Demandan las ḥaločentas

y las niñas poberetas

no les queda cajaretas ${ }^{96}$

para los acontentar.

\section{Mujeres a la moda}

El texto procede de la siguiente fuente única:

- Versión aljamiada publicada en el periódico de Salónica Acción (2) 10/2588 (1938) p. 3c.- Cabecera general: «Muestros regalos y las complas de Purim»; precede al texto: «Aźkir hasasdé El neemán» ${ }^{97}$ (Baecs 257b).

Copla inédita y anónima, que consta de 4 quintetas de rima aaacd, siendo corto el v. $d$.

1 Hoy las niñas son eśbeltas, todas flacas siluetas, muchas haćen las dietas por ser suples, delgadicas y miñón.

2 Todas con bucles peinadas, las puatrines aparadas, mušos, caras coloradas, tacos altos, parecen haćer tentés.

3 Es de ver a las caśadas con medios velos cuafadas, enteras enpudreadas que parecen, que parecen mascarás.

4 Se vengan de los maridos que van siempre acoridos, te los dejan descoridos por sus quiefes por la moda y el čhic.

\footnotetext{
${ }^{96}$ Según Nehama s.v. kašaréta la palabra significa 'taba'; debemos entender que a las chicas ya no les quedan recursos.

97 'Recordaré las clemencias del Dios fidedigno', inicio de uno de los piyutim hebreos propios de la fiesta de Purim.
} 


\section{LOS BAILES MODERNOS}

Para ilustrar el apartado me sirvo de tres textos ${ }^{98}$.

\section{Los males del charlestón}

El texto procede de las siguientes dos fuentes:

- A: Versión oral de Esmirna publicada por Levy Chants II núm. 53 (p. 52), con melodía.

- B: Versión oral de Bienvenida Aguado-Mushabak (Çanakale, Turquía) grabada por Susana Weich-Shahak en Bat Yam (Israel) en 1991 y publicada por la propia colectora en ¡En buen simán! núm. 56b (p. 173), con melodía y traducción al hebreo.

Canción tradicional, que fecho por aproximación en ca. 1920. En la versión A consta de una estrofa de cinco versos, y en la B de 3 estrofas de tres versos que tienden a rimar los dos primeros (menos en estr. 4), acabando el tercero siempre en charlestón.

\section{Versión 14.A}

1 Mamá, mírame las gambas

que las tengo malas

de tanto bailar.

Cuando bailo charlestón

me s'alegra'l corazón.

\section{Versión 14.B}

1 Esto, esto es el baile,

la pena vale

de bailar charlestón.

2 Cada día penando, al viernes asperando para jueves bailar charlestón.

3 Mamá, háćeme la cama que 'stó cansada de bailar charlestón.

\footnotetext{
${ }^{98}$ Sobre los nuevos bailes que se habían puesto de moda en el mundo sefardí vid. HavassY New Texts pp. 14-15 y la bibliografía que recoge en notas. Allí, amén de los que aquí se mencionan, figuran también la rumba y el vals.
} 
4 Mamá, mércame calzados

que me s'estruyeron

de bailar charlestón.

\section{El foxtrot}

El texto procede de la siguiente fuente única:

- Versión aljamiada publicada en el libro Los cantes de La Trompeta (Salónica marzo 1924, Edición de La Trompeta) p. [12].- En portada: «...3] Foxtrot plaćentero»; cabecera: «Fox-trot plaćentero; se canta al son del muevo y hermośo fox trot "To mavro rodo"» (en letras latinas) ${ }^{99}$.

Poema inédito firmado por el seudónimo de «Siyac» (Efrayim Ŝiyón), que consta de 3 estrofas numeradas en arábigos de 10 versos, seguidas la estr. 1 de un «Refrain» (la palabra en letras latinas) de 7 versos, la estr. 2 solo de las palabras «al Refrain» (de nuevo Refrain en letras latinas) sin que siga el texto, y la estr. 3 sin ninguna remisión.

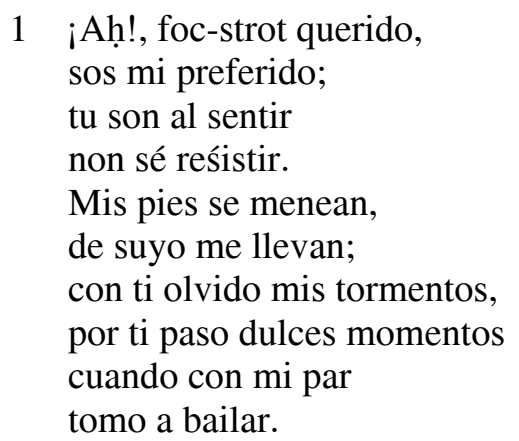

¡A cómo el foc-strot haće plaćer.

Él rinde horośos y venturośos ${ }^{100}$, siendo con él puedéš alcanza[r] en bailándolo a... aḅrazar ciertos busticos muy... ricos, ¡ah..., ah...!

\footnotetext{
${ }^{99}$ El número 3 de la portada no se corresponde con el lugar que el texto ocupa en el libro, ya que figura tras el que en dicha portada se numera «10] Morenas y biondas». En cuanto a la melodía, CONEJERo «Cantes satíricos» (Apéndice núm. 6, nota 51), quien como he indicado en

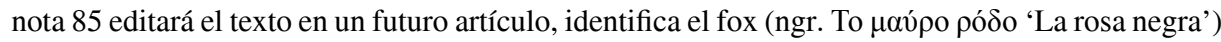
como procedente de la opereta homónima.

${ }^{100}$ Escrito por error ventośos.
} 
2 Las niñas d'agora quieren cada hora el foc-strot bailar con algún buen par... Por esto los niños, por ser d'ellas diños, en las academías cale que vayan embeźar el baile, si non no pueden ver... ganeden ${ }^{101}$.

3 Con los bailes muevos hay ciertos mancebos que van a bailar para s'encontrar con las bailaderas que haćen dalaveras. Ahí es las conversaciones, después abren sus... corazones y después... también te ${ }^{102}$ dan... sus... bien.

\section{Pasos de baile}

El texto procede de la siguiente fuente única:

- Versión aljamiada publicada en el libro 12 Cantes populares de Saḍic y Gaśóś ([Salónica ca. 1924]: edición La Vara) p. 12 (Havassy New Texts núm. II).- En portada: «... 12) Las niñas cuando bailan»; cabecera: «Las niñas cuando bailan, se canta al son del cante turco y grego" [ל'Ymatá pws plynys rwháa]"».

Poema inédito firmado con el seudónimo de «Mošico» (= Mošé Abraham Caźés [Gaśóś]). Havassy New Texts (pp. 53 y 78) reproduce algunos fragmentos con traducción al hebreo.

Consta de 6 estrofas -numeradas en arábigos, excepto la primera- que son aleluyas emparejadas, seguidas de sendos «Refrén»-sólo numerado el tercerodel mismo esquema estrófico.

1 Ande quieres que las falles, en las grutas, en las calles,

\footnotetext{
${ }^{101}$ Escrito גאנידין; cfr. hb. גן עדן Gan 'eden 'el Paraíso'.

${ }^{102}$ Escrito por error se.
} 
haź atanción a los pasos, se meten lunares falsos ${ }^{103}$.

Parecen que van bailando, cómo menean lo blando ${ }^{104}$..., la puatrín, miśmo la talla, prontas para la batalla.

2 Cuando bailan a la turca -el chalguí non queda nunca-, las niñas echan papadas ${ }^{105}$ y los hombres dan patadas ${ }^{106} \ldots$

A pasico meśurado y el puerpo estirado, mucho duź llevan el puerpo para non piedrer el tiempo.

3 Al foxtrot, landras con pintas ${ }^{107}$, ahí te las haćen pitas ${ }^{108}$; hay de enclavar la mano sin pueder dećir en vano. Las caricas apegadas, las niñas son espulgadas; y el niño, ande toca, la niña demanda choca ${ }^{109}$.

4 En los vestidos delgados los niños, sin ser rogados,

${ }^{103}$ Alude a la costumbres de las mujeres de aquellos años de ponerse lunares en la cara y en sitios estratégicos.

${ }^{104}$ Que hay que suponer que se refiere a las nalgas.

${ }^{105}$ Nehama s.v. papáda explica la expresión ečar papada como 'se rengorger, se pavaner, s'étaler'.

${ }^{106}$ Amén del sentido obvio, vid. tb. Nehama s.v. patáda en donde recoge la expresión dar patadas que traduce, entre otras cosas, por 'exiger quelque chose avec insistance'.

${ }^{107}$ NeHAMA s.v. lándra recoge la expresión landras kon pintas ke son dos komidas que traduce 'ulcères pestilentiels et fièvre typhoïde, souffrances et tourments, rebuffades et injures à la place d'un résultat concret, tangible à quoi on s'attendait [...]'.

${ }^{108}$ NeHAma s.v. píta recoge la expresión fazer a uno pita que traduce 'battre quelqu'un avec cruauté; faire subir à quelqu'un une grave humiliation publique'.

${ }^{109}$ La palabra me ofrece dudas de comprensión. No parece tratarse aquí de la que recoge NeHAMA s.v. čóka 'camada; clueca' y también 'tipo de juego'; por su parte PEREZ - PIMIENTA s.v. chuka traducen 'miembro viril, pene' y en lenguaje infantil 'pipí', pero no veo claro que lo que pida (demanda) la chica sea una de esas dos cosas. Y hay que tener en cuenta también tc. çoka, çuka 'caviar, huevas de esturión', que podría tratarse de la petición de la joven como compensación a tanto manoseo. 
topan todo amanado:

hey se les va el ganado ${ }^{110}$.

La niña media deśnuda,

la carne liša y carnuda,

a el niño emboracha

con cachetas en la facha ${ }^{111}$.

5 Al guán step hay otra cośa:

la niña apetitośa

quita fuego de sus venas

al cašterear ${ }^{112}$ las piernas.

Apegan las pechaduras,

si son blandas, si son duras;

yo digo que hay espanto

de este dulce contacto.

6 El tango es la balanza:

la niña manco se cansa;

la distancia es muy corta, hey se emplea la punta...

Por atrás o adelantre...

lo que se ve es deśastre;

lo que manca a la dama

es laboro de la cama ${ }^{113}$.

\section{LAS RELACIONES ENTRE CHICOS Y CHICAS: PROCESO DE SEDUCCIÓN}

Como decía en el artículo madre «Emancipación», para ilustrar este grupo temático, en el que abundan los textos, incluyo solo diez que me han parecido especialmente ilustrativos de la situación, dejando otros muchos en el tintero.

\section{El gancho}

El texto procede de la siguiente fuente única:

- Versión aljamiada publicada en el librito de Alexandro Pérez̧, Buqueto de cantes compośados por_—y Las muevas complas del felec ([Salónica ca. 1920], Edición Čharló; Estamparía Beźés) (Baecs 223) p. 16.- En por-

\footnotetext{
${ }^{110}$ Es decir, lo que han ganado, su dinero.

${ }^{111}$ Es decir, ruborizándose, poniéndose colorada; cfr. NeHAma s.v. kačéta.

${ }^{112}$ Nehama s.v. kaštereár 'mêler [...]' remite a tc. kaştirmak, que no he encontrado.

${ }^{113}$ Parece decir, que llegados a este punto, a la mujer ya sólo le falta que la lleven a la cama.
} 
tada: «... 13. El gancho...»; cabecera: «El gancho..., baile guán-step (se canta al son de la cantiga grega "או סירטים [<'W syrtym>]")».

Poema inédito de Alexandro Pérez̧, que consta de 3 estrofas divididas en dos bloques, formadas por dos cuartetas de rima $a b a b$, que van seguidas de sendos «Refrén» de ocho versos de rima aabbaaba, siendo el verso cuarto igual en todas las estrofas y con formulación similar al tercero.

1 Hay un chico istrumento

que, malgrado su chiquez, mos sierve algún momento... por pátah y por camés ${ }^{114}$.

Es del gancho que yo quiero hablarvos, visto que es un pedacico de fiero de muy grande interés.

Cale reconocer que nunca puede ser que sin meter el... gancho, el... gancho, el... gancho, se pueda entender el gusto con plaćer: cale meter el gancho bueno y a dober.

2 Cuando estás embuelvido con una hanum del dor en un lugar escondido por praticar el amor..., non vayas en lo escuro por haćerte hovardá..., vate en lugar seguro: en buró o en udá ${ }^{115}$.

\footnotetext{
${ }^{114}$ Las palabras, escritas respectivamente (פתח (hb. פאטיס (2amés), son los nombres que reciben las dos vocales con sonido $a$ del hebreo, la primera similar a un guioncito y la segunda como un pequeña te versal, que se escriben debajo de las consonantes a las que acompañan. NeHAMA s.v. pátaj explica la expresión vale por pataj y por kames como 'cela sert à la fois, ex aequo, à deux usages différents', es decir y como diríamos en español, referido a algo que vale tanto para un fregado como para un barrido.

${ }^{115}$ La recomendación al joven es que no se haga el galante, llevándose a la moza a un lugar donde no los puedan ver; preferible es ir a un lugar cerrado (un despacho o una habitación de hotel), aunque muchos los vean.
} 
Si quieres bien estar y sin te espantar, cale meter el... gancho, el... gancho, el... gancho.

Para sentir mejor el pasto, la sabor, cale meter el... gancho, el asegurador.

3 Cuando tienes una polla que non sabe la lición... y quieres que sea tuya, toma grande precución.

Sea tadre o temprano por la calle non estés; aférala de la mano, llévala en un cafés.

Si le quieres hablar... sin miedo, sin temblar, cale meter el... gancho, el... gancho, el... gancho.

Ansí aribarás

a lo que tú quierás...; mete pišín el... gancho y me bendećirás.

\section{El mal de los bailes}

El texto procede de la siguiente fuente única:

- Versión aljamiada publicada en el librito Los cantes de La Trompeta (Salónica marzo 1924: Edición de La Trompeta) p. 9.- En portada: «... 9] A la debučh»; cabecera: «A la debučh; se canta al son del hermośo uán step “' או סירטיס'W syrtys $>]$ '”

Poema inédito firmado por el seudónimo de «Conjá», que consta de 3 estrofas denominadas, respectivamente, «Tercio [sic] cuplé», «Segundo cuplé» $\mathrm{y}$ «Terzo [sic] cuplé», formadas por dos cuartetas de rima $a b a b$, seguidas de sendos «Refrén» de 8 versos y rima $a a b b c c b c$.

${ }^{116}$ En el número anterior la segunda palabra del nombre de la melodía aparece escrita al final con mem en lugar de con sámej. El texto lo editará también CONEJERO «Cantes satíricos» (Apéndice núm. 5), quien no dice nada respecto a la música. 
1 Con el baile y la moda, el luso, los decoltés, cas̀i la mancebez toda están con gran despiertez.

Los bracicos roś deśnudos haćen mucho exitar; lišos, frescos y carnudos, niños, ¿sabéš profitar?

Se saben aplicar y también pelizcar con lo que arescuña la uña..., la uña... Por non dejar batal lo que es santimantal, se deǰan sin ensuña robar el capital.

2 Las miradas y las riśas los haće šešerear; de hey nacen las sorpreśas después de arepotrear. Las caras unas con otras, las tallas abrazadas, la mirada se encontra, las pachás apretadas.

Se toca el faldar para se exitar con lo que arescuña la uña..., la uña... Con pudra y boya la bruna o roya se deja sin ensuña entera engrobiñar.

3 Tienen raźón los mancebos que non se quieren caśar: los haćen unos culebros las que se dejan beśar. Venden barato sus puerpo por non pueder alcanzar ${ }^{117}$;

${ }^{117}$ Quizá lo que no pueden alcanzar es un novio formal. 


\author{
ansina pasan el tiempo \\ con engañar y falsar. \\ Con hẹen y con ĝilvés, \\ con mucha diablez, \\ con lo que arescuña \\ la uña..., la uña... \\ se deǰan apalpar \\ lo que deben tapar; \\ se dejan sin ensuña \\ carezar y beśar.
}

\title{
19. El mal de las niñas
}

El texto procede de la siguiente fuente única:

- Versión aljamiada publicada en el librito Cantes populares de Ŝdic y Gaśóś publicados en El Culebro y La Vara (Salónica, feḅrayo 1924, edición de La Vara) p. 2 (Havassy New Texts núm. I).- En portada: «... 1) El mal de las niñas»; cabecera: «El mal de las niñas; cante "J́aźbán"».

Poema inédito compuesto por Saḍic y Gaśóś. Havassy New Texts (pp. 49-50) reproduce y traduce al hebreo algunos fragmentos.

Consta de 2 estrofas formadas por dos bloques, respectivamente, de 8 versos y rima $a b a b c c c b$ y de 10 versos y rima $a b a b c c b d d d$, seguidas de sendos «Refrén» formados por otros dos bloques de 9 y 11 versos, el primero de rima $a b a b c c d d d$ y el segundo de rima ababccddeee.

1 El mal de las niñas ya salió a taburá ${ }^{118}$; de verlas indiñas ya se toman sehorá. Los lusos tan deśmodrados de los brazos remangados, ya se ve fin a los lados, ¿quien ve qué dirá?

Los tacos bien altos, parecen haćer tentés;

${ }^{118 \mathrm{Hb}}$. תרבות רעה tarbut ra ‘á 'depravación'; Nehama s.v. taburrá recoge la expresión salir a taburra que traduce 'être en plaine confusion, ne plus savoir où donner de la tête, ne plus savoir à quel saint se vouer, perdre la boule'. 
van echando saltos

con sus largos decoltés.

Los braćicos roś carnudos,

lišos, frescos en deśnudos;

hablan con muy polités,

espiertez...,

esbeltez...;

ansí dan la contentez...

Ellas frecuentan el dancing

para ir encontrar

mancebicos bien exantric

que saben manobrar...

El foxtrot en una figura

o el tango en derechura

con apretar

sin heśitar,

ansí las saben excitar.

Con budras, llenas de parfum,

en los mušos color,

se chupan como el locum,

sus beśos dan sabor.

Los separés son las sorpreśas, las atiran con sus sonriśas

$\mathrm{y}$ sin pensar

dejan pasar

sin haćer mucha atanción

los que provocan con pasión

la corupción.

2 Los más condanables

son los niños del dor;

son los responsables

que depiedren la pudor.

A las niñas las engañan, sus moralitás se dañan,

la honor ellas encañan

con falso ardor.

Fachas arapadas

y peinados a la bros, haćen serenadas, 
miśmo que non tienen yoz.

Condurias, calzas de seda, portefolios sin moneda; visten chico papilión muy miñón, embrolión, a la fin es un campión.

Hijicas, vos espanden red, bušcan de vos cachar: metiéndolos ${ }^{119}$ a la pared, non vos dejeéš manchar.

Con sus palabras punchunośas, con sus fineźas de rapośas, saben falsar y carezar, el tiempo saben bien pasar ${ }^{120}$. Madres, si quieréš sus honor, debéš sobreguadrar; si non quieréš sus deśhonor, cale acavidar a vuestras hijas con prudencia que non acorden la licencia al falsador, engañador que bušca haćer impresión con ideas de traición. ¡Ma atanción! ${ }^{121}$.

\section{La coqueta y su destino}

El texto procede de la siguiente fuente única:

- Versión aljamiada publicada en el librito Cantes populares de Sadic y Gaśóś publicados en El Culebro y La Vara (Salónica, febrayo 1924, edición de La Vara) pp. 8-9 (Havassy New Texts núm. I).- En portada: «... 7) La coqueta y su destino»; cabecera: «La coqueta y su

${ }^{119}$ Con valor de imperativo: ponedlos.

${ }^{120}$ Es decir, saben divertirse, pasar el tiempo.

${ }^{121}$ Como conclusión el mensaje que se da a las madres es el de que presten mucha atención a lo que hacen sus niñas. 
destino; se canta al son de "מי גלונדי קי מו פ'לירט" $m w>$ flirt]"».

Poema inédito de Ŝadic y Gaśóś. Havassy New Texts (pp. 83-84) reproduce, comenta y traduce al hebreo un fragmento.

Consta de 3 estrofas formadas por dos bloques de 7 versos y rima ababccc seguidas de sendos «Refrén» formados por 8 versos de rima $a a b b c c x c$.

1 Me llaman la frivol, me place reír; bebo mucho alcol y no sé sufrir. Luso y caḅaré, dancing y separé y siempre visto yo caré.

Yo so una mujer, me plaće fumar; ma sé bien escoǵer y lo sé quemar: al mancebo habil echo al źembil y le tomo muchos de mil.

Con la ĝilvéś, con sonreír una veź, lo impresiono, me empatrono de su pasión; ma con negra inteción fin vaćiar su portefolio, después: traición.

2 Me sé bien maquiar, non hay que dećir: me plaće pasear para seduićir.

Yo me sé entender y con precio vender, mis defetos sé esconder.

Yo bušco ĝentilhom por lo escorchar; 
bebo ḥašíš, opium

por me borachar.

Al balo, con giilvéś,

quemo la mancebez

y todo yolto a revéś.

Vo al bufé,

me llaman calorifé...

Bebo čhampaña,

quien me acompaña

le sé robar

y entero escarbar ${ }^{122}$.

Que sea bruno o royo

avante sé trabar ${ }^{123}$.

3 Las ruhas, la edad, saben desformar;

solo con probedad me saben hormar ${ }^{124}$.

Al fondo, al cantón, mis güesos un montón, envejecida con bastón.

Escapo con sufrir

la tuberculóśs ${ }^{125}$;

la hora de muerir

no hay una yoź.

¿Quién me va llorar

y quién va suspirar

y con estera enterar ${ }^{126}$ ?

Hec la moral:

las niñas en ǵeneral

${ }^{122}$ Lo que le escarba (saquea) es la cartera.

${ }^{123}$ NehAmA s.v. travár recoge la expresión travar avante que traduce por 'resquiller', es decir, 'sisar, sacar el dinero'.

${ }^{124}$ Quizá se trate de la raíz hb. $\square$ \ ח h.r·m y de los sustantivos derivados de esa raíz -hérem, ḥormá 'destrucción, desastre'-; pero quizá haya también que tener en cuenta tc. hirman 'frustración, desesperación'.

${ }^{125}$ Escrito turḅeculóś, que no sé si se trata de error gráfico o si se está remedando una forma popular de pronunciar la palabra.

${ }^{126}$ Parece querer decir que morirá arruinada y que, por mortaja, la envolverán en una estera de esparto. 


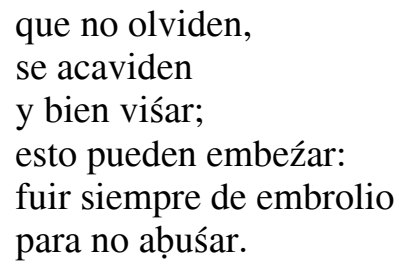

\section{Las faldas cortas}

El texto procede de la siguiente fuente única:

- Versión aljamiada publicada en el librito 12 Cantes populares de Sadic y Gaśóś ([Salónica ca. 1924]: edición La Vara) pp. 8-9 (Havassy New Texts núm. II).- En portada: «... 8) Corto»; cabecera: «Corto..., se canta al son del hermośo guán-step "Ya de lu muguet", cante francéś que tuvo un succeso loco al dancing-caḅaré Tur-Blančh ${ }^{127}$ : "Ya des loups Muguette"» (ahora en caracteres latinos).

Poema inédito de Ŝạic y Gaśóś. Havassy New Texts (pp. 58 y 78-79) reproduce, comenta y traduce al hebreo un fragmento.

Consta de 3 estrofas numeradas en arábigos - menos la primera- de 10 versos que son pareados encadenados, seguidas de sendos «Refrén» igualmente numerados en arábigos de 7 versos y rima aabbccc.

1 Vos quiero hablar y so costreto

lo que veo en cada momento: con la moda del estrecho y corto faldar al diablo mos van a mandar.

La moda de los vestidos cortos las mujeres mos mostran sus frutos con sus calzas beš y las condurias de lustrín, bombé se les haće la puatrín.

Las formas de las tallas, al mostrar sus redondez, parecen dos canones, formas de otós blindés.

Faldares con ${ }^{128}$ fustas transparán, cuantos mancebos al ver suspirarán lo que mostran al subir al tram, sea demuaśel o sea bien madam. de baile.

${ }^{128}$ Escrito son. 
Sin penetrar

saben mostrar,

al fuego mos saben entrar.

2 Se ven piernas flacas, también godras, unfladas saliendo de las bodras ${ }^{129}$;

hay piernas de cuclas fechas a el tallator ${ }^{130}$, sale loco el qu'es amator ${ }^{131}$.

La pachá una enriba d'otra,

blanca, liša, ella mo la mostra;

cortos los cabellos se los saben arapar,

parecen bonbones de chupar.

¿Por qué mos mostran sin quierer y sin les arogar

la pierna roś carnuda de el más mejor lugar?

Yo al punto vo lo vo dećir

el efeto que se puede produićir:

cuantas mostran sus panoramas...

y ansí los hombres non reśisten más.

Vo señalar

que al bailar

cośicas dan de consolar...

3 Cuando las vemos en los balcones

o al subir de los escalones,

cuando mostran gambas que haćen šešerear

non conviene más eśvariar...

La moda de cašcoles de seda

el hombre apercantado queda;

cale ver los balos, también en los suarés, lo que dejan ver de los carés.

Las carnes roś y frescas se las dejan apalpar, ¿a cuándo, dunque, las pachás se van a destapar?

Moda, ¿ánde mos vas a llevar?

Por te alcanzar cale ir a robar;

de la mujer haćes un juguet,

${ }^{129}$ No me queda muy claro de dónde salen las piernas gordas, si bien cabe suponer que se esta refiriendo al borde inferior de las cortas faldas. La palabra no tiene aquí el sentido que recoge Nehama s.v. bodrá de 'corteza de pan'; y no sé si puede ponerse en relación con tc. potur, que NehAma s.v. potúr traduce 'braie, culotte bouffante du paysan turc, de l'homme du peuple de jadis'.

${ }^{130}$ Parece decir que algunas piernas parecen hechas por un escultor, un tallista.

${ }^{131}$ Es decir, se vuelve loco el que es aficionado a las mujeres (cfr. fr. amateur). 


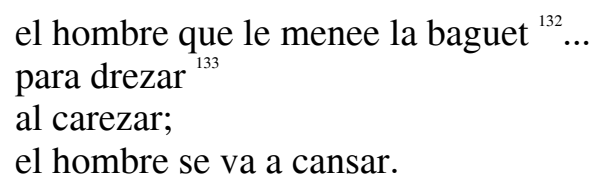

\section{Los chicos y las chicas}

El texto procede de la siguiente fuente única:

- Versión aljamiada publicada en el librito 10 Cantes populares de Sadic y Gaśóś, Cinquena sería (Salónica [ca. 1926]: edición del Riśón, estamparía Beźés) p. 14 (Havassy New Texts núm. V).- En portada: «... 10. Las pollicas muevas»; cabecera: «Las pollicas mиevas... y los gallos de el dor, es el cante final o el cante comic que se escapa con un porpurí siendo se canta al son del cante turco " מינוש [Amán <mynwšs ${ }^{134,}$ o al son que vos plaće».

Poema inédito firmado con el seudónimo de «Mošico» (= Mošé Abraham Caźés [Gaśóś]). Consta de 8 cuartetas de rima abab que se inician todas con jạ̣! y llevan como estribillo la frase «Amán menúš».

1 ¡Aḥ!, las niñas que tienen daño yoltan cara al chuflar ${ }^{135}$ y se dejan con engaño apalpar en el bailar. Amán menúšs.

2 ¡A !̣!, cuando pasan las ḥaninas todos las salen a ver; son como las tallarinas que se dejan bien sorber. Amán menúšs.

3 ¡A A !, por las biondas y las royas: son lechón ${ }^{136}$ con havaviar;

${ }^{132} \mathrm{Cfr}$. fr. baguette, que por lo de menear puede tratarse aquí de 'batuta', pero que, indudablemente, puede tener un segundo sentido, aludiendo al órgano sexual masculino.

${ }^{133}$ Cfr. fr. dresser 'poner derecho, enderezar' y tb. 'idear un plan' y 'hacer entrar en vereda', pero no sé a qué se refiere.

${ }^{134}$ Sobre la identificación de la melodía vid. Havassy New Texts Apéndice II p. 192 y sobre este estribillo p. 99.

${ }^{135}$ Entiendo que quiere decir que se vuelven cuando los chicos las silban por la calle.

${ }^{136}$ Que no se trata de la cría del cerdo, alimento prohibido para los judíos; NeHAMA s.v. lečón traduce la palabra como 'laitance (du poisson mâle)', es decir, en esp. 'lecha, lechaza'. 
en las caras tienen foyas cośa de maraviar. Amán menúš.

4 ¡A Ạ!, sangre dulce las morenas y las que tienen lunar, manean senos y piernas con ĝilvéś al caminar. Amán menúš.

5 ¡Aḥ!, peás friśadas y bucles y las calzas de color, mos mostran pejes ${ }^{137} \mathrm{y}$ muscles que dan bascas y calor. Amán menúš.

6 ¡Ah!!, los niños que sin fostanas quedos no pueden estar, las niñas quieren bananas, ellos les dan a gustar. Amán menúš.

7 ¡Ah!!, cašcoles, guetres y fiongos, riźás de punta al ĝep; los remendos de los bogos mostran al bailar guanstep. Amán menúš.

8 ¡Aḥ!, los vestidos abultados, chapeos al boyaĝ́, gaḅardinas emprestado tomadas del esquiĝ́í. Amán menúš.

\section{Los señoritos y las criadas}

El texto procede de la siguiente fuente única:

- Versión aljamiada publicada en el librito Los cantes de La Gata (Salónica agosto 1927) p. 5.- En portada: «... 3. Los musiús y las

${ }^{137}$ Nehama s.v. péše ('pez') recoge las expresiones el peře de la pačhá y el peře del braso que traduce respectivamente como 'le mollet' y 'le biceps'; lo que quiere decir es que las chicas enseñan brazos y piernas. 
servideras (Valentine)»; cabecera: «Los musiús... y las servideras, se canta al son de "Valentine"»"

Poema inédito firmado al pie del texto por lo que parece un seudónimo «Lionel de Mesoï»; consta de 2 estrofas denominadas «Cuplé»-numerada solo la segunda en arábigos-, formadas por 10 versos de rima $a a b b b c$ $c d d d$, seguidas de sendos «Refrén» de 12 versos y rima abbaacddceec.

1 Ciertos mancebicos se contan señores, también les parecen que son profesores.

Aires se quieren dar, ma non saben meldar, de política quieren hablar.

Ellos no sḥacharon ni un sólo banco ${ }^{139}$, ma también se quieren dar aires de franco.

Non tienen ni pendar, ma detrás del faldar corren... sin quedar.

$\mathrm{Al}$ dancing salen a taburrá, con las niñas tienen tiñas.
$\mathrm{Al}$ dancing deśhaćen la pará ${ }^{140}$ con Marica y Sará; visten todos moda charlestón, son hạadrośos y babośos. En sabá tienen bastón, en semana, non hay gana ${ }^{141}$, tienen remendo al pantalón.
2 Lo de las mocicas es un mal aparte. ¡A !̣!, caro amigo, quiería contarte. Muchachas de servir

\footnotetext{
${ }^{138}$ En ambos casos la palabra Valentin en letras latinas. CONEJERo editará el texto en su futuro artículo «Cantes satíricos» (Apéndice núm. 2).

${ }^{139}$ Como decir, no calentaron el banco de ninguna escuela, no han estudiado.

${ }^{140}$ Es decir, pulen su dinero.

${ }^{141}$ Nehama s.v. gána recoge la expresión paralela de estar sin gana que traduce 'manquer d'entrain'; es decir, como el sábado se han gastado todo lo que tenían, el resto de la semana están de pésimo humor y sin ganas de nada.
} 
quieren yir a yivir

en lugares que va el guebir.

Al dancing se acienden en una braśa, tadre en la noche atornan en caśa.

Si toman a pensar, se van a vergüenzar

la hora de... caśar.

Las tadres salen a pasear

como locas,

non son pocas.

Les plaće mucho cudurear, con los niños curear.

Como la madam quieren vestir,

elegantes

y con gantes

se quieren bien divertir;

ma algunas

comen prunas ${ }^{142}$ :

dolor de tripa hay consentir ${ }^{143}$.

\section{Padres e hijos}

El texto procede de la siguiente fuente única:

- Versión aljamiada publicada en el librito Los cantes populares de Sa dic y Gaśóś (Salónica mayo 1928: edición del Riśón, Imprimería J́ośef Catán) p. 11 (Havassy New Texts núm. VI).- En portada: «... 8. Niños y niñas (charlestón italiano)»; cabecera: «Niños y niñas; se canta al son del cante italiano charlestón "Papá y mamá"».

Poema inédito de Ŝạic y Gaśóś; consta de 3 estrofas numeradas en arábigos salvo la primera de 7 versos de rima $a a a b c c b$, seguidas de sendos «Refrén» de 9 versos numerados también en arábigos y rima variable.

1 Vimos tantas cośas, que para las explicar, para las haćer trocar, cale criticar.

${ }^{142}$ Nehama s.v. prúna recoge la expresión komer pruna que traduce 'faire une mauvais affaire, éprouver une grosse perte', es decir, que tienen graves disgustos y problemas.

${ }^{143}$ Entiendo que alude a que pueden quedarse embarazadas. 
El mal de el luso tomó grande perpusión ${ }^{144}$ y ansina

hoy combina

que hay corupción.

Las niñas van escondidas de mamá, con achac de bailar

en el dancing o en algún cinemá;

sin se ver controlar,

pasan ahí muchos momentos,

sea en la loj̣a o benuar,

y a mamá

te la saben curear ${ }^{145}$, no penan para la engañar.

2 Hoy las niñas a los niños quieren imitar con los cabellos cortar

y por ajustar

propios como hombres visten čharpas con yacás, largas cejas, las orejas

con godras hạalcás.

Corto faldar y la jaquet mucho cločh

condurias de lamé,

yacás duḅlé con papilión de suá fločh:

hey gastan el sermé.

De punta la riźá al pecho

y chapeico de castor;

y es mamá,

en lugar de corejar,

las flata con mucho caentor.

3 Los niños van locos con la moda charlestón, con el baile blac botón

por cada cantón.

\footnotetext{
${ }^{144}$ Que no sé exactamente qué quiere decir; quizá que ha crecido, que está teniendo mucha repercusión.

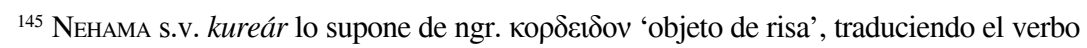
por 'se moquer', lo que supondría que aquí quiere decir que se burlan de sus madres. Por su parte CONEJERO «Cantes satíricos», piensa que se trate de tc. kur yap- 'flirtear', si bien ese significado convendría mejor a la palabra en el contexto de 23 Señoritos (estribillo tras estr. 2). En cualquier caso, lo que quiere decir es que no les cuesta trabajo engañar a las madres.
} 


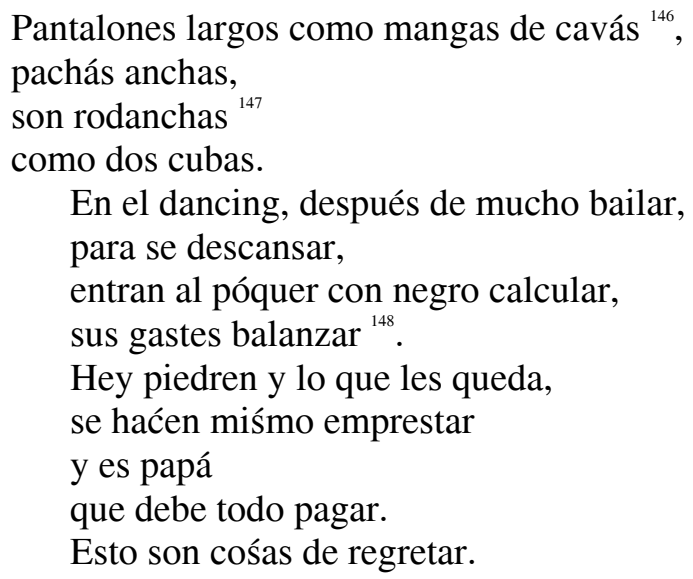

\section{Las coqueterías femeninas}

El texto procede de la siguiente fuente única:

- Versión aljamiada publicada en el librito Los cantes populares de Ŝadic y Gaśóś (Salónica 25 marzo 1933: edición de El Rayo, Biḅlioteca del Rayo, Tip. Popular) p. [7] (Havassy New Texts núm. X).- En portada: «... Muestras bijuquilas ("Congré s'amúś")»; cabecera: «Muestras bijuquilas; se canta al son del alegre foxtrot "מים טו חורו" hiwrw>]" del filmo "Le congres s'amuse"» (en letras latinas).

Poema de Saḍic y Gaśóś, editado por Havassy New Texts (pp. 134136).

Consta de dos estrofas denominadas «Cuplé» y numeradas en arábigos de 8 versos y rima $a a b c c b d d$, seguidas de sendos «Refrén» numerados en arábigos de 14 versos y rima aabccbddeffegge.

1 Es de reír

que al següír

las demuaśeles muy čhic,

con sus fedor

146 Supongo que quiere decir, que son muy anchas.

${ }^{147}$ Entiendo que quiere decir que son cilindros muy anchos; NEHAMA s.v. rodánča anota el significado de 'pâté formé par un long fuseau cylindrique farci à volonté de fromage, d'épinards, de purée de potiron, etc., et enroulé en spiral'; a tal cosa deben parecerse los pantalones de los chicos.

${ }^{148}$ Es decir, se ponen a jugar al póquer haciéndose el cálculo equivocado de que así van a cubrir gastos. 


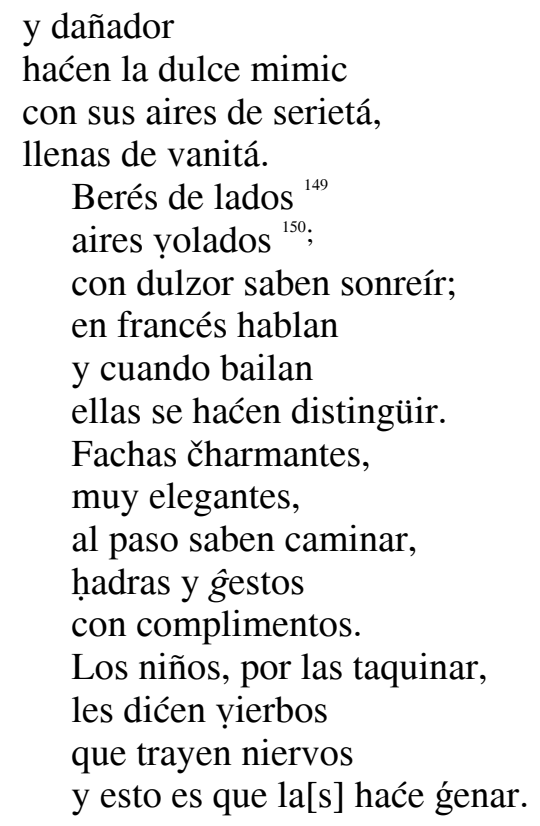

2 A dos, a tres, si veš sus tres ${ }^{151}$

llenas de far y boyas.

Por ondular y regular se cortan cejas, peás, se haćen bucles y friśés, las caras dos beśés ${ }^{152}$.

Se rapan cejas;

miśmo las viejas aires se dan de juventud; corsés, sutienes,

${ }^{149}$ Es decir, con boinas ladeadas.

${ }^{150}$ Nehama s.v. áyre recoge la expresión es un ayre bolado que traduce 'c'est un individu superficiel, une tête de linotte'.

${ }^{151}$ Palabra que en apariencia repite la misma palabra de rima del verso anterior, pero que aquí se trata de fr. traits, es decir, 'sus rasgos, sus caras'. Agradezco a Rivka Havassy tal precisión.

${ }^{152}$ Aquí con el sentido de 'merengues' (cfr. fr. sing. baiser 'beso'), que puede aludir tanto al dulzor como a los colores suaves del dulce. De nuevo agradezco a Rivka Havassy esta precisión. 
mostran los bienes,

las formas que dan inquietud.

Muchas, descalzas, sonriśas falsas

haće[n] para mos provocar.

$\mathrm{Al}$ baño mixto, - ¿esto fue visto?-

al niño lo van a bušcar.

Ma en invierno

sus amor tierno

al dancing se van por se pelizcar.

\section{La cuarentona}

El texto procede de la siguiente fuente única:

- Versión aljamiada publicada en el librito Los cantes populares de Sadic y Gaśóś (Salónica abril 1935: edición del Rayo, Biḅlioteca del Rayo, Tip. Populara) p. [6] (Havassy New Texts núm. XI).- En portada: «... En fablando de París»; cabecera: «Los que preferan la mujer de 40 años, se canta al son del cante popular grego אי סאראנדארה $[<' Y$ sarandará $>$ ]"».

Poema inédito de Ŝạic y Gaśóś; consta de un total de 10 estrofas numeradas como sigue: precede a la primera la indicación de «Cuplé 1» y a la segunda «Refrén 1», indicaciones que no vuelven a repetirse; las tercera y cuarta están ambas numeradas 2; las quinta y sexta, 3; las séptima y octava, 4; y las novena y décima, 5 . Debo entender que tras las dos primeras se ha prescindido de las indicaciones de «Cuplé» $\mathrm{y}$ «Refrén» $\mathrm{y}$ que los números repetidos corresponden siempre al «Refrén», de ahí mi presentación. Se trata en todos los casos de cuartetas de rima $a b a b$.

1 No amo las hijicas

frescas y delicadas;

ma quiero mujericas

un poco aedadas.

Porque las jovenicas

son cas̀i lo más locas;

sean probes o ricas,

las que pensan son pocas.

2 Por esto yo prefero

la mujer de cuarenta, 
porque no haće yero

ni al dancing frecuenta.

La chica es coqueta,

no sabe que fardarse;

amá la de cuarenta

sabe sacrificarse.

3 La jóvena, gavienta, no quiere que espejo; ma la qu'es de cuarenta te puede dar consejo

La chica a la cama demanda muchas cośas; la de cuarenta, calma, vale para ventośas ${ }^{153}$.

4 La chica, caprichośa, nunca se acontenta; es manco despechośa la mujer de cuarenta.

Siempre la chiquitica

se quiere controlada;

ma la aedadica

es hecho y colada.

5 Por esto, mis amigos, quien quiere que me sienta: manidas ${ }^{154}$ como figos ya son las de cuarenta.

Vos digo a la oreja $\mathrm{y}$, si quieréš, probando ${ }^{155}$ : que la gaína vieja asolta mejor caldo.

[Continuará]

${ }^{153}$ Que quizá quiera decir que sirve hasta para poner ventosas.

${ }^{154}$ NeHAMA s.v. manído recoge la expresión mužer manida que traduce 'femme qui ne peut plus avoir des prétentions à la fraîcheur de la jeunesse', pero que por su comparación con los higos, también podríamos entender como 'dulces' o 'blandas'.

${ }^{155}$ Con valor de imperativo. 